J. Lake Sci. (湖泊科学), 2014, 26(3):331-339

http://www. jlakes. org. E-mail : jlakes@niglas.ac.cn

(C) 2014 by Journal of Lake Sciences

\title{
古湖沼学研究揭示湖泊生态系统服务变化的过程”
}

\author{
徐 敏,董旭辉,羊向东** \\ (中国科学院南京地理与湖泊研究所湖泊与环境国家重点实验室,南京 210008)
}

\begin{abstract}
摘 要: 当今在气候变化和人类活动等多重压力影响下, 作为地表过程重要组成部分的湖泊生态系统正遭受着巨大威 胁, 其服务功能急剧退化. 如何客观地评价湖泊生态系统服务的现状,并科学地预测其发展趋势, 是当前亟待解决的问 题. 开展长期生态系统服务变化过程与机理的分析, 有助于未来生态系统服务变化趋势的预测. 然而, 现有的观测数据往 往时间较短 (通常小于 50 年). 连续的湖泊沉积记录为研究生态系统服务变化的长期过程提供了可能. 本文结合前人研 究成果, 列举了可反映湖泊生态系统服务变化的一些古湖沼学指标, 依据这些指标相对明确的生态和环境指示意义, 将 其与各项服务关联起来. 最后,结合巢湖实例分析来说明这些指标在评估湖泊生态系统服务方面的具体应用,研究表明 当今巢湖生态系统服务供应能力的持续增加是以调节服务的丧失为代价的. 尽管目前的研究尚处于起步阶段,但古湖沼 学手段无疑为今后湖泊生态系统服务历史状况的评估提供了途径, 为古湖沼学的应用提供了一种新的思路, 并为今后生 态系统的保护和可持续利用提供重要的决策依据.
\end{abstract}

关键词: 湖泊;生态系统服务;历史过程;古湖沼学;沉积物指标

\section{Using paleolimnology to reconstruct historic processes of lake ecosystem services}

\author{
XU Min, DONG Xuhui \& YANG Xiangdong \\ ( State Key Laboratory of Lake Science and Environment, Nanjing Institute of Geography and Limnology, Chinese Academy of \\ Sciences, Nanjing 210008, P. R. China)
}

\begin{abstract}
With the impacts of climate change and human activities, lake ecosystem nowadays is suffering from multiple threats and its services function becomes degenerated. It is urgent to evaluate objectively the value of the lake ecosystem services and to predict their future state. Understanding the historical evolution process of ecosystem services and its mechanism is crucial for predicting the future changes of ecosystem service. However, most of the existing instrumental record on ecosystem service is too short $(<50$ a). With continuous sedimentation, lake sediments can provide detail information on the long-term changes of the lake ecosystem services. With a review on previous studies, this paper introduced a few palaeolimnology indexes that can be linked to various forms of lake ecosystem service. We also presented a case study of Lake Chaohu to demonstrate how the implementation of these proxies could indicate the lake ecosystem services. This study showed that the growth in economy and production supply capacity is always at the cost of the loss of regulating services of lakes. Although such kind of research is still in its infancy, there's no doubt that it will be of great benefit to palaeolimnology development and can provide a scientific basis for decision making in the protection and sustainable utilization of lake ecosystem in the future.
\end{abstract}

Keywords: Lake; ecosystem service; historical process; palaeolimnology; sedimentary proxy

生态系统为人类提供了直接或间接的产品和服务, 使人类享受福祉. 然而, 人类往往只重视生态系统具 有的直接提供产品的能力, 如粮食、水源、木材、药品等, 对生态系统的间接服务功能却关注不够. 近些年随 着人类活动的日益加剧, 诸多环境问题涌现,生态系统的间接价值及生态效用逐渐被人们所关注. 1949 年,

* 国家自然科学基金项目 (41102105)、湖泊与环境国家重点实验室开放基金项目和教育部留学回国人员科研启动 基金项目联合资助. 2013-06-24 收稿; 2013-11-21 收修改稿. 徐敏(1987～), 女,博士研究生; E-mail: min.minxu@163.com.

** 通信作者;E-mail:xdyang@ niglas. ac. cn. 
美国学者 Leopold 首次思考了生态系统的 “服务”功能, 指出生态系统服务功能是其它系统所不能替代的 ${ }^{[1]}$. 20 世纪下半叶, 有学者陆续开始对生态系统服务进行深人研究 ${ }^{[2-7]}$, 生态系统服务逐渐成为地理学、生态学、 环境科学等诸多学科关注的重要内容. 关于生态系统服务, 目前虽尚无统一的定义, 但众多科研人员都认可 把人类从生态系统获得的各种惠益统归为生态系统服务, 它包括供给 (食物、水、纤维和燃料等)、支持 (初级 生产力、生物多样性、土壤维持力等)、调节 (气候调节、水质等) 和文化 (精神、美学、消遣和教育等) 4 大类 ${ }^{[8]}$.

湖泊生态系统作为地球生态系统的重要组成部分, 对于保障流域内人们的生产生活及区域经济的可持 续发展具有举足轻重的作用. 地球现有湖泊面积约 $2.7 \times 10^{6} \mathrm{~km}^{2}$ (约占大陆面积的 $1.8 \%$ ), 我国现代天然湖 泊面积也在 $9 \times 10^{4} \mathrm{~km}^{2}$ 以上 ${ }^{[9]}$. 作为天然的蓄水库, 湖泊既能够蓄积湖区渍水、防涝减灾、供应淡水, 又可以 调节局地降水与气温, 同时还是各类水生动植物的优良产地, 对于生物多样性的维持意义重大. 然而, 新中 国成立以来, 经济的飞速发展加剧了人们对于湖泊资源的开发与利用. 掠夺性的资源利用方式和非可持续 性政策的实施等使得湖泊生态系统正遭受严重威胁, 各种环境问题突出, 如富营养化、外来物种人侵和生物 多样性降低等 ${ }^{[10]}$. 如何合理地利用湖泊资源并有效保护湖泊生态系统的服务功能, 是当下科学工作者和环 境管理人员必须面对的问题.

气候变暖和强烈人类干扰, 使得湖泊生态系统的未来充满了不确定性. 对未来变化趋势的准确预测, 必 须了解湖泊生态系统长期变化的特点. 然而, 目前的资料多是基于年鉴记载或有限的现代观测数据, 后者的 时间尺度往往过短 (一般不超过 50 年). 湖泊沉积物中保存了丰富的生态系统变化的信息, 其连续的、高分 辨率沉积记录是刻画湖泊和流域长期变化的良好载体 ${ }^{[11]}$. 很长一段时间以来, 古湖沼学手段主要用于对湖 泊生态和环境演化历史过程的重建, 以揭示湖泊生态系统中各组分相互作用的关系. 可喜的是, 随着对各种 沉积环境代用指标机理认识的不断深人, 已有学者开始尝试将古湖沼指标与湖泊一流域生态系统服务功能 指标 (如水质、生物多样性、土壤质量与持久力等) 建立联系, 来揭示生态系统服务的长期变化过程 ${ }^{[12]}$.

本文着重介绍了可用于指示湖泊生态系统服务的古湖沼学代用指标, 以及如何利用这些功能性指标来 揭示湖泊生态系统服务的状况及变化趋势. 在此基础上, 以长江中下游浅水湖泊一一巢湖古湖沼研究为实 例, 分析了巢湖过去 200 年来生态系统服务功能指标的变化, 探讨了生态系统调节服务的变化与气候变化 和人类活动的关系. 最后讨论了古湖沼学技术在湖泊生态系统服务长期变化研究的潜力和今后发展的 方向.

\section{1 湖泊生态系统服务功能与相关指标}

\section{1 湖泊生态系统服务功能}

生态系统服务包括 4 大功能, 即供给服务、调节服务、支持服务和文化服务. 对湖泊生态系统而言, 供给 服务提供了包括食物、淡水和遗传资源 3 个主要功能. 首先, 湖泊是重要的食物供应地, 提供了人们赖以生 存的各种鱼类、软体动物和某些水生植物资源. 对湖泊中鱼类等食物种类和数量的测定有益于了解湖泊生 态系统的供给状况. 其次, 湖泊作为流域重要的淡水资源, 为流域人口和经济的发展提供了重要的水源. 许 多世界大河流域下游的洪泛平原区, 历来也是耕作农业的发源地, 湖泊和湿地淡水资源的变化已成为制约 流域灌溉农业发展的重要因素之一. 此外, 湖泊另一个重要的服务功能在于对遗传资源的传承和保护. 作为 重要的淡水生态系统, 湖泊孕育了众多的水生动物、植物与微生物, 它们的存在对湖泊生态系统多样性的维 持意义重大. 近些年来, 由于不合理的人类活动等导致了高等水生维管束植物与底栖生物分布范围缩小, 浮 游植物 (藻类) 等大量繁殖并不断集聚形成生态灾害, 湖泊生物多样性遭到不同程度的威胁 ${ }^{[10]}$.

湖泊生态系统的调节服务主要涉及对水质、旱涝和气候调节 3 个方面. 湖泊生态系统具有水质净化功 能, 水质的变化将直接影响流域居民的用水安全, 如 2007 年太湖蓝藻的暴发就曾导致过流域周边数百万人 的用水困难. 通过湖泊的营养指标和重金属分布的调查和测试可以反映其水质和沉积环境状况. 湖泊生态 系统还是淡水资源的重要储存器和调节器, 在调蓄洪水方面作用巨大, 尤其对于我国东部平原区, 湖泊承担 的防洪功能在保障流域居民安居乐业方面的地位更是举足轻重 ${ }^{[10]}$. 对湖泊水位和湖内泥沙淤积速率的长期 监测可以掌握湖泊水量的变化情况. 湖泊生态系统还有调节气候的能力, 相对于周边地区, 湖区往往气温变 
率更小, 降水更多. 通过对于湖区温度、降水、蒸发量的长期监控结果可以很好地反映这一点. 值得一提的 是, 最近一些相关研究表明, 湖泊还是重要的碳储存库,通过测定湖泊沉积物中的有机碳等可以反映湖泊生 态系统对于温室气体 $\mathrm{CO}_{2}$ 的固定作用 ${ }^{[13]}$.

湖泊生态系统内的光合作用和营养物质的循环等均属于湖泊生态系统支持服务的范畴. 这些服务虽然 目前无法直接用经济价值来衡量, 却是湖泊生态系统正常运转不可或缺的重要服务内容. 湖内水生植物和 藻类初级生产力与生物量的测定可反映湖泊生态系统光合作用强度, 通过相关生物地球化学等方法可了解 湖内营养物质循环状况 ${ }^{[14]}$.

湖泊生态系统的文化服务涉及多方面的内容,除了景观美学、休闲娱乐、孕育文化外,还是重要的科研 和教育基地. 然而,所有这些文化服务的实现无疑需要其它服务的支持与配合. 目前这类服务只有部分内容 可用直接指标反映, 大多数服务很难用直接方法获得. 例如湖泊的景观美学需要优美的自然风光、清新的空 气以及种类多样的生物等共存才能实现,这些都无法用单一的指标来完成.

\section{2 湖泊沉积物指标揭示的生态系统服务长期变化}

湖泊沉积物中的各种物理、化学和生物指标记录了流域与湖泊变化的过程. 这些指标有着相对明确的 生态与环境指示意义,能够反映特定的生态系统服务长期变化过程的信息. Dearing 等 $^{[12]}$ 依据国际 “千年生 态系统综合评估 (MA)” 分类标准, 分析了沉积物中各种代用指标对湖泊一流域生态系统服务功能性指标 (如水质、植被生物多样性、空气质量、土壤质量与持久力等) 的指示作用. 表 1 列举了一些古湖沼学相关沉 积代用指标, 并依据这些指标的物理意义,分析它们与湖泊生态系统服务功能指标的关系,进而建立与供给 服务、调节服务和支持服务之间的联系.

表 1 湖泊生态系统服务的古湖沼学代用指标

Tab. 1 Palaeolimnology proxies as surrogate of lake ecosystem services

\begin{tabular}{|c|c|c|c|c|}
\hline \multicolumn{2}{|c|}{ 生态系统服务类别 } & \multirow{2}{*}{$\begin{array}{l}\text { 直接指标 } \\
\text { 鱼类及其生物量 } \\
\text { 特定的水生植物 }\end{array}$} & \multirow{2}{*}{$\begin{array}{l}\text { 沉积物代用指标 } \\
\text { 动物残骸和水生植物残体 }\end{array}$} & \multirow{2}{*}{$\begin{array}{r}\text { 参考文献 } \\
{[16,18-20]}\end{array}$} \\
\hline 供给服务 & 食物 & & & \\
\hline & 淡水 & 盐度、水量和水位 & $\begin{array}{l}\text { 盐度重建指标、浮游/底栖硅 } \\
\text { 藻比值、浮游/底栖枝角类比 } \\
\text { 值/自生碳酸盐等 }\end{array}$ & {$[21-22]$} \\
\hline & 遗传资源 & 生物多样性等 & $\begin{array}{l}\text { 各类生物种群组成与丰度、 } \alpha \\
\text { 和 } \beta \text { 多样性 }\end{array}$ & {$[17,23-25]$} \\
\hline \multirow[t]{4}{*}{ 调节服务 } & 水质净化 & 水体和沉积物营养 & $\begin{array}{l}\text { 水体营养重建值、沉积物有机 } \\
\text { 碳、氮、磷 }\end{array}$ & {$[26-27]$} \\
\hline & & 重金属 & 铅、永、砷等 & {$[28-29]$} \\
\hline & 抗洪减涝 & 水位、泥沙淤积速率 & $\begin{array}{l}\text { 粒度、沉积速率、沉积通量、浮 } \\
\text { 游/底栖硅藻比值、浮游/底栖 } \\
\text { 枝角类比值 }\end{array}$ & {$[30]$} \\
\hline & 气候调节 & 碳固存 & 无机碳和有机碳累积速率 & {$[13]$} \\
\hline 支持服务 & $\begin{array}{l}\text { 光合初级生产力、 } \\
\text { 营养物循环等 }\end{array}$ & $\begin{array}{l}\text { 水生植物和藻类初级生产力 } \\
\text { 与生物量、生物地球化学 }\end{array}$ & $\begin{array}{l}\text { 硅藻、水生植物残体、各种藻 } \\
\text { 色素、碳和氮同位素 }\end{array}$ & {$[31-32]$} \\
\hline 文化服务 & $\begin{array}{l}\text { 休憩/旅游/教育/ } \\
\text { 美学等 }\end{array}$ & 水质、生物多样性、其它 & - & - \\
\hline
\end{tabular}

保存在湖泊沉积物中的大多数生物遗存, 目前已有成熟的实验室分析技术 ${ }^{[15]}$. 然而, 一些大型动物残体 如鱼类骨骼、双壳类和螺类等,由于其沉积的偶然性和间断性,往往很难被检出,或者在沉积地层中不连续, 而这些大型动物却提供着非常重要的湖泊生态系统服务,如食物供给. 此时,往往需要借助其他的指标间接 揭示这方面信息. 例如,湖泊沉积物中枝角类残体能间接地反映鱼类生物量. 枝角类是无脊椎动物,主要栖 息于蔓生水草的浅水沿岸区和敞水区,一些特定浮游种类如象鼻溞与鱼类之间存在明显的被捕食与捕食的 关系. 因此,鱼类直接通过捕食来影响水体中枝角类的种类构成和数量. 如食鱼性鱼类的引人或数量的增加 
可导致浮游生物食性鱼类的灭绝,进而引发其他浮游动物捕食者如摇蚊类丰度的增加, 最终使得某些小型 枝角类如象鼻溞的数量急剧减小 ${ }^{[14]}$. Jeppesen 等 ${ }^{[16]}$ 通过对丹麦 30 个浅水湖泊表层沉积物中枝角类进行分 析, 揭示了其与鱼类生物量之间存在的显著相关关系, 由此建立了二者之间的转换函数. 因此, 沉积物中的 枝角类化石可作为一种有效的生物指标来指示过去湖泊中鱼类的变化, 进而反映湖泊生态系统食物供给服 务的变化. 可食用的水生植物种类有限, 可以依据保存在地层中的植物残体的鉴定和数量统计获得, 并通过 其浓度和沉积速率计算生物量. 花粉分析也能指示特定的水生植物如眼子菜、荇菜、芦苇等历史生长信息.

淡水资源为生活和生产用水提供了保障, 湖泊水体的盐度和水量变化是直接的衡量指标. 近年来古湖 沼学发展了重建过去水体盐度的方法, 但这个方法目前只适用于干旱和半干旱地区湖泊的历史重建. 沉积 物中的自生碳酸盐等地化指标也通常用于干旱区湖泊水环境的恢复. 对淡水湖泊, 生物指标可以有效指示 水深的变化特征. 例如根据沉水植物与挺水植物丰度的相对变化、硅藻以及枝角类中浮游种/底栖种比值, 可以定性地恢复湖泊不同演化阶段水位和水量的相对变化 ${ }^{[14]}$.

沉积钻孔中各类生物种群组成与丰度, 记录了时间序列上属种种类数目, 以及稀有种、常见种、优势种 和外来人侵种的组成变化特征. 利用统计分析手段, 还可以计算不同门类生物 (如硅藻、水生植被) 种群多样 性变化指数. 这些信息是构建湖泊生物种子库和揭示生物多样性变化的重要依据. 通常, 多样性指数高时表 明湖泊生态系统能够提供的遗传资源多, 湖泊生态系统服务功能强; 反之, 则代表湖泊生态系统无力提供遗 传资源, 生物多样性减退 ${ }^{[17]}$.

湖泊营养状况和重金属含量是衡量水质变化的直接指标, 关系到生态系统的安全与健康. 在湖泊沉积 物中, 直接指示营养变化的指标是沉积物中的氮、磷和有机碳含量, 反映重金属污染的元素包括铅、录、砷和 铜等. 然而, 沉积物氮、磷和有机碳含量主要反映沉积环境的变化, 对历史时期一直是草型湖泊来讲, 这些营 养元素的变化并不能反映当时湖泊水体营养浓度的状况, 尤其是受人类活动干扰的湖泊 (如长江中下游的 龙感湖等). 近年来, 随着转换函数的应用, 历史时期湖水总磷或总氮浓度得以定量重建 ${ }^{[14]}$, 可以更全面了 解时间序列上生态系统对水质净化的调节服务功能的变化过程.

湖泊是淡水资源的重要储存地和中转站, 在流域水资源供给和洪水调蓄方面发挥着不可替代的作用. 粒度作为湖泊沉积学与古气候研究中的传统指标, 是指示区域降水、湖泊水位波动等诸多古气候环境信息 变化的良好指标. 一般来说, 湖泊流域的水动力系统受流域植被和降水的影响较大, 而对于湖泊自身内部的 水动力系统, 则主要受水位的影响. 在排除流域植被和降水的影响下, 可用粒度 $(>64 \mu \mathrm{m})$ 来反映湖泊自身 的水动力状况: 即沉积物中粗颗粒物质增多, 指示湖泊水位升高, 表明湖泊能够提供调蓄服务; 反之, 指示湖 泊水位下降, 湖泊对洪水的调蓄能力降低 ${ }^{[14,30]}$. 当然, 影响湖泊分异的因素很多, 湖泊面积、湖区地形、所处 气候带和降水性质以及取样孔沉积相类型等都影响粒度的平面分布和垂向变化, 即往往有多解性, 因此分 析湖泊沉积粒度分异的主要因素和规律需参照其他代用指标进行综合研究 ${ }^{[14]}$. 在洪泛平原区, 历史时期湖 泊围层、泥沙淤积数量和淤积速率变化也是影响洪涝发生的重要原因之一. 通过钻孔沉积物年代测定计算 的沉积速率和沉积通量以及前面提到的浮游/底栖硅藻比值、浮游/底栖枝角类比值恢复的水位变化可以提 供干旱和洪港变化过程的信息.

越来越多的研究结果表明: 湖泊在有机碳循环方面发挥着重要作用 ${ }^{[33-34]}$. Dong 等 ${ }^{[13]}$ 通过对长江中下游 地区众多湖泊的碳储量进行估算, 结果表明湖泊是重要的碳库, 湖泊有机碳的现储量与其面积之间存在显 著关系. 再如, 全球湖泊全新世以来沉积物中碳储量 $\left(4 \times 10^{14} \sim 8 \times 10^{14} \mathrm{~kg}\right)$ 高达陆地生物量的 2 倍, 达到陆地 土壤和生物量中碳储量的 $25 \% \sim 50 \%{ }^{[34]}$. 对湖泊总有机碳和无机碳的累积量的测定, 同时结合湖泊沉积孢 粉和摇蚊一气候因素转换函数对历史温度和降水的重建, 有助于我们了解湖泊在碳循环、气候调节方面所起 的重要作用,更好地界定湖泊气候调节服务的变化过程.

湖泊生态系统服务提供了光合初级生产力、营养物循环等重要支持功能, 包括湖泊沉积物中水生植物 和藻类初级生产力与生物量的变化、生物地球化学行为和过程. 稳定同位素地球化学方法可以通过对湖泊 沉积物中有机质、生物壳体的碳同位素研究来探讨湖泊沉积物中有机质的来源及其初始生产力的变化, 并 判断有机质形成时的环境状况; 有机地球化学方法则根据湖泊沉积物中色素的含量和种类来了解藻类生物 群落的结构, 恢复湖泊的初级生产力; 水生植物残体和硅藻的通量计算 (浓度 $\times$ 沉积物干通量) 可以指示水 
生植物和硅藻生物量的变化 ${ }^{[14]}$. 上述地球化学和古生态指标均可作为湖泊生态系统服务的良好代用指标, 反映其支持服务的变化历史.

目前利用古湖沼指标反映文化服务功能, 尚有一定的难度,主要原因是无法用特定的指标反映休喤、旅 游、教育、美学等功能. 如上所述, 文化服务及其变化必须通过上述几项服务功能的变化进行综合评估.

\section{2 研究实例一一以长江下游巢湖为例}

本文以长江下游巢湖钻孔沉积记录的分析结果为例, 来说明古湖沼学手段在湖泊生态系统服务研究中 的具体应用.

巢湖位于长江北部, 地处安徽省中部, 是我国五大淡水湖之一. 现水面面积为 $770 \mathrm{~km}^{2}$, 平均水深为 $3.1 \mathrm{~m}$. 该区属亚热带季风区, 冬季冷干, 夏季暖湿多暴雨, 巢湖水位变化呈现出冬枯夏涨特点. 受相应水位和流域 地形等的影响,该区平均每 $4 \sim 6$ 年就有 1 次中等强度的洪涝灾害. 沿湖区农业以水稻种植业为主,但近些年 来,由于气候变暖、人类围垦等使湖区耕地结构发生变化,水田面积减少, 旱地增加; 水利设施配套不到位, 使灌溉面积减少,耕地质量明显下降. 除此之外, 不适当的毁林开荒等也使得森林植被减少,加剧了水土流 失. 巢湖历史时期水生动、植物种类丰富.《巢湖市志》中记载的巢湖中水生植物包括偋类如满江红 (Azolla imbricata)、槐叶藻 (Salvinia natans), 单子叶植物如蒲草 (Typha angustifolia)、芦苇 (Phragmites communis)、菖 蒲 (Acorus calamus), 双子叶植物如水花生 (Alternanthera philoxeroides)、金鱼藻 (Ceratophyllum demersum) 、苂 (Euryale ferox)、菱(Trapa) 等,这些都曾广泛遍布于湖中; 鱼类有约上百种,其中银鱼、白米虾、螃蟹被誉为 “巢湖三珍” ${ }^{[35]}$. 建国后随着经济的发展, 人湖的废水逐年增多,2010 年巢湖东半湖 6 个监测点显示综合污 染指数在 $6.10 \sim 7.35$ 之间, 富营养化指数在 $48.6 \sim 54.4$ 之间 ${ }^{[36]}$. 水质富营养化诱发蓝藻暴发, 水质变差, 湖中的水生动植物也因此受到影响.

本文利用 2007 年在巢湖西北湖区中心附近采集的沉积钻孔 ( C1 孔) 进行研究 ${ }^{[37]}$. 该钻孔中分析的沉积 指标包括狍粉、硅藻、有机碳、氮、沉积物磷、元素地球化学、粒度、沉积物干通量等,钻孔年代序列用 ${ }^{210} \mathrm{~Pb} 、{ }^{137} \mathrm{Cs}$ 和 ${ }^{14} \mathrm{C}$ 建立. 本文只对钻孔上部 $40 \mathrm{~cm}$ 段沉积指标数据进行分析, 该深度以上代表了过去 200 年的沉积记录, 年代框架的建立和各指标的具体分析方法参考文献 [37].

虽然生态系统服务涉及的内容众多, 然而对于我国东部长江中下游的大多数湖泊来说, 现今最主要、最 严峻的问题莫过于湖水的富营养化、生物多样性下降、防洪减涝能力减退等 ${ }^{[10]}$. 生物多样性所表征的遗传资 源供给原则上虽属于供给服务,但在本文, 考虑到生物多样性对于维持湖泊生态功能方面起到的重要作 用 ${ }^{[38]}$, 其支持和调节功能远大于其供给能力, 所以此处把它归为调节服务. 采用水质指标 (水质净化服务, 图 1a)、沉积物质量指标( 水质净化服务, 图 1b)、泥沙调节能力指标(侵蚀调节服务,图 1c) 和生物多样性指 标(遗传资源服务,图 1d) ,分析湖泊及其流域生态系统调节服务的长期变化.

第 $1 、 2$ 项指标均为反映湖泊一流域生态系统水质净化服务能力的沉积代用指标. 第 1 项指标代表水质， 用成熟的硅藻一总磷指标转换函数方法来推断过去湖水总磷浓度进而反映湖泊对水质的调节能力, 高值代 表湖泊对水质的净化能力差, 反之亦然. 第 2 项指标代表沉积物质量, 因浅水湖泊沉积物中的磷与流域农业 活动等有关, 故用沉积磷含量指示流域耕作土壤的流失, 高值代表湖泊一流域生态系统无力提供水质净化能 力. 第 3 项指标代表湖泊生态系统侵蚀调节能力, 人湖泥沙量可以反映沉积物的侵蚀与流域存积土壤之间 的平衡关系,指标值高,代表湖泊一流域地形无力提供侵蚀调节服务. 第 4 项指标代表湖泊生态系统对基因 资源的供给状况, 用狍粉植物类群丰富度指数近似代表湖泊甚至相关流域植被的多样性,高值表明湖泊一流 域生态系统能够维持生物多样性,反之则代表无力维持.

将上述具体的沉积物指标均值化处理, 即将各指标值分别按其大小比例标准化成 $0 \sim 1$ 间的各值, 再将折算后的 4 个指标值取综合平均数, 以此作为湖泊生态系统调节服务综合指数. 汇聚成的湖泊生 态系统调节服务 $(R S)$ 综合曲线则代表 1800 年来巢湖地区湖泊及其流域生态系统调节服务功能整体 变化情况 (图 2).

1800 年以来,水质状况一直较好, 至 1980s (历史上对应改革开放时期) 开始恶化 (图 1a). 与水质变化情 况类似,沉积物质量自 19 世纪至 20 世纪中期一直维持在较高水平,20 世纪中期以后(历史上对应中华人民 

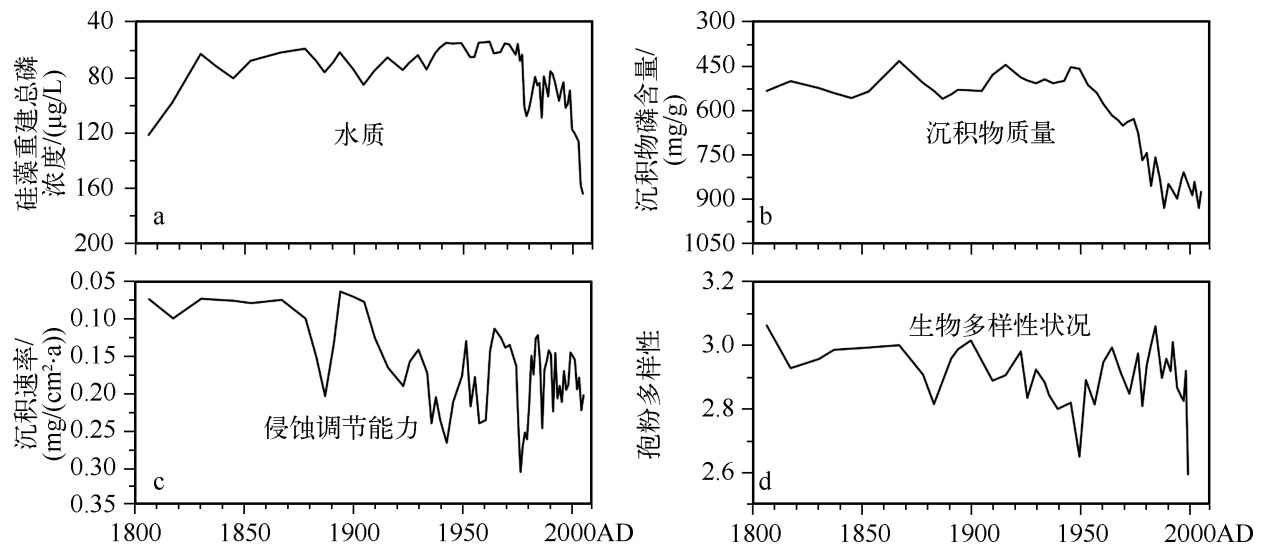

图 1 过去 200 年来巢湖生态系统服务多指标变化情况

Fig. 1 Ecosystem service changes for water quality, sediment quality, soil stability and biodiversity in Lake Chaohu in the past 200 years

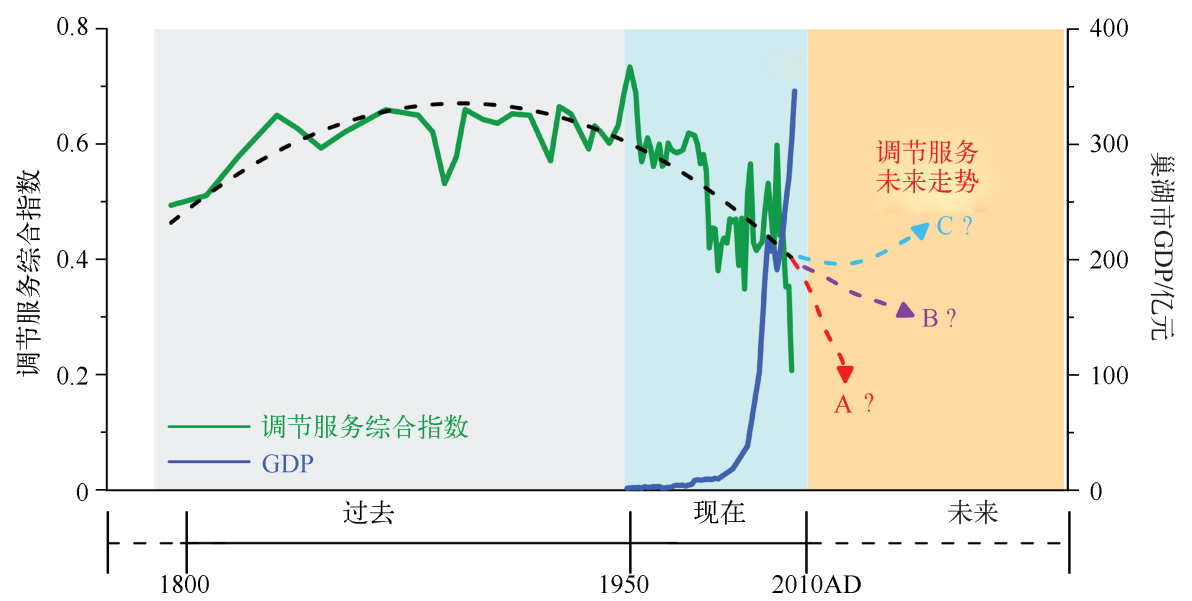

图 21800 年来巢湖湖泊生态系统调节服务综合指数和巢湖市 GDP 变化情况

Fig. 2 Integrated index of regulating service of Lake Chaohu ecosystem and GDP of Chaohu City since 1800

共和国成立后), 沉积物质量逐渐降低 (图 1b). 侵蚀调节能力总体呈现减弱趋势, 整体变化波动较大, $1880 \mathrm{~s}$ 末、1940s - 1950s 以及 1970s 末是几个显著减弱时期(图 1c). 生物多样性曲线在 200 年间均呈现波动, 但无 明显波动趋势,但 20 世纪中期和 21 世纪以来,生物多样性水平较低.

结合图 2 可知, 1800-1950 年, 调节服务 $(R S)$ 综合指数整体较高,除去 $1880 \mathrm{~s}$ 后期有一次显著波动外, 总体相对平稳; 1950 年后 $R S$ 指数开始下滑, 1970 年后降低速率加快, 进人 21 世纪, 这种降低趋势越发显 著. 19 世纪初至 20 世纪中期, 所有的调节服务相对来说较强且稳定, 表明当时的湖泊一流域生态系统总体状 况较好. $1880 \mathrm{~s}$ 后期 $R S$ 指数波动是由于生物多样性和侵蚀调节能力遭到减弱造成的. 据历史资料记载 ${ }^{[35]}$, $1880 \mathrm{~s}$ 巢湖流域经历了一次大旱灾,相关湖区居民因无粮而大量围捕、挖掘各类动植物, 导致生物多样性减 少, 湖泊一流域也因缺少植被保护而导致侵蚀调节能力减弱. 1949-1980 年,生物多样性、沉积物质量和侵蚀 调节能力均向下波动, 导致这一时期的调节服务显著减弱: 1949 年新中国成立以后, 巢湖地区开展了轰轰烈 烈的恢复生产运动, 水利工程的建设、森林的砍伐和农业集体化使得生物多样性急剧下降, 大面积的化肥施 用等导致沉积物质量下降, 裸露的地形又使得水土流失加剧, 湖泊一流域地形侵蚀调节能力也因此减弱. 1980s 后, 调节服务的变率开始增大, 进人 21 世纪之后, 调节服务水平降至历史新低. 沉积物质量貌似在 
1990 年以后就维持稳定了,这可能归功于小型灌溉和淤地坝的增加; 而 1990 年后侵蚀调节能力开始保持相 对稳定是 $1980 \mathrm{~s}$ 后环境成功管理 (如植树造林) 的证据. 尽管如此,水质却在 1980 年后开始变差,2000 年以 后是水质持续恶化最快的几年, 渔业养殖化肥施用量升高、人湖污染物增多等使得巢湖水质持续恶化. 进人 21 世纪以来,城镇化建设使得生物多样性又进人了新的快速衰退阶段. 这些显著衰退的水质、生物多样性、 沉积物质量、侵蚀调节能力表明了调节服务退化已达顶峰, 正如调节服务综合指数所显示的, 它由 1950s 的 0.72 跌至 2006 年的 0.24 ( 图 2).

对比相应流域巢湖市 GDP 数据可知 (图 2), 新中国成立以来, 在集约种植、工业进步的背景下, 本区域 经济显著发展,代表经济发展状况的 GDP 数据持续走高. 但 GDP 与巢湖生态系统服务综合曲线呈现的负相 关性在一定程度上表明,经济的增长、供应能力的增加往往以生态系统服务的损害为代价. 人们片面地关注 从生态系统获取的直接价值, 而忽略了其生态效用,把经济的发展建立在对自然生态系统的破坏之上. 图 2 中 A 型轨迹基于过去 200 余年巢湖生态系统调节服务功能变化趋势的数学预测, 表明随着人类对湖泊资源 的篗取, 湖泊生态系统最终完全丧失其调节服务功能. 事实上, 尽管巢湖周边居民继续保持现今的这种生 产、资源利用方式,但湖泊自身及社会管理机构会对这种持续恶化状况有一个自身的调节过程, 因此, 巢湖 未来湖泊生态系统的调节服务功能可能将沿图 2 中 B 型轨迹发展, 但整体呈下降趋势. 很明显, C 型轨迹描 述了一种非常理想的湖泊资源利用方式,即需要在政府相关政策调控及更科学的湖泊管理方式的条件下, 生态系统状态逐渐好转, 生态系统的调节功能也将持续改善. 由此可见,过去长尺度的生态系统服务变化曲 线的建立,无疑为我们定量刻画了在长时间尺度上湖泊生态系统服务功能的变化,也为不可持续性资源利 用方式下未来生态系统服务功能的恶化敲响了警钟, 提供了很好的科学依据.

\section{3 结论与展望}

针对古湖沼学长时间尺度记录的优势, 将其与湖泊的各项生态系统服务类别相挂钩, 建立相应指标评 价体系, 以此来反映湖泊生态系统各项服务的长期变化趋势, 为我们正确评估生态系统服务提供了有效途 径. 结合巢湖的实例研究表明,古湖沼学指标可以为生态系统服务的变化建立评估框架. 对巢湖地区湖泊沉 积物的分析, 揭示了其湖泊生态系统的供给能力往往建立在调节服务功能损害的基础之上, 该湖湖泊生态 系统服务的变化, 特别是最近数十年来, 并非遵循可持续发展之路.

当然,将古湖沼学技术应用于湖泊生态系统服务研究还存在一些局限性. 首先从指标本身来说, 古湖沼 学指标具有多解性, 影响它的因素并不唯一, 所以选用古湖沼学参数来间接反映生态系统服务变化具有一 定的不确定性. 将来的工作中, 需要尝试综合多种可反映同一服务的代用指标,利用多指标的分析结果来消 除单项指标的多解性所带来的不确定性. 其次, 尽管现代测年手段较过去已显著改善, 但目前基于 ${ }^{210} \mathrm{~Pb}$ 、 ${ }^{137} \mathrm{Cs}$ 等方式确立百年以上的沉积物年代仍然存在一定误差 ${ }^{[39]}$. 因此,在阐述生态系统服务功能时间上的变 化特征,如变率、生态系统服务退化的具体时间等需谨慎. 第三, 由于不同湖泊具有不同的地理背景特征, 人 类对不同湖泊生态系统的利用方式上也存在时空差异. 未来在研究特定湖泊的生态系统服务变化时, 需要 多考虑湖泊的特殊地理背景, 不能一概而论. 最后, 在反映生态系统整体服务状况时,生态系统的各项服务 对当地居民的重要性并不一致. 在进行生态系统服务功能综合价值评估时, 如何考虑各种服务形式间的权 重是一个复杂且重要的问题,可尝试在特定地理背景下通过专家决策系统、问卷调查等形式考虑对各指标 施以权重, 从而更合理地体现湖泊生态系统综合服务变化情况.

尽管将古湖沼学手段应用于湖泊生态系统服务研究还存在诸多局限,但毫无疑问,古湖沼学手段是我 们现今获得历史时期湖泊生态系统服务演化信息的唯一手段,该类指标框架的建立和完善为今后湖泊生态 系统服务历史状况的评估构建了初步框架,也为今后生态系统的保护和可持续利用提供了重要的科学决策 依据.

致谢: 感谢英国南安普敦大学 John Dearing 教授、中国科学院南京地理与湖泊研究所王苏民研究员及王㭉副 研究员对本文提出宝贵意见.

\section{4 参考文献}

[ 1 ] Leopold A, Schwartz CW, Bradley NL et al. A sand county almanac and sketches here and there. Oxford: Oxford 
University Press, 1949.

[ 2 ] SCEP. Man's impact on the global environment: Study of critical environmental problems. Boston: MIT Press, 1970.

[ 3 ] Holdren JP, Ehrlich PR. Human population and the global environment: Population growth, rising per capita material consumption, and disruptive technologies have made civilization a global ecological force. American Scientist, 1974, 62 : 282292.

[ 4 ] Daily GC. Nature's services: Societal dependence on natural ecosystems. Washington DC: Island Press, 1997.

[ 5 ] Costanza R, d'Arge R, de Groot R et al. The value of the world's ecosystem services and natural capital. Nature, 1997, 387: 253-260.

[ 6 ] Cairns J. Protecting the delivery of ecosystem services. Ecosystem Health, 1997, 3 (3) : 185-194.

[ 7 ] Fu BJ, Wang S, Su CH et al. Linking ecosystem processes and ecosystem services. Current Opinion in Environmental Sustainability, 2013, 5(1): 4-10.

[ 8 ] Assessment ME. Ecosystems and human well-being: Synthesis. Washington DC: Island Press, 2005.

[9] 王苏民,窦鸿身. 中国湖泊志. 北京: 科学出版社,1998.

[10］杨桂山,马荣华,张 路等. 中国湖泊现状及面临的重大问题与保护策略. 湖泊科学,2010,22(6): 799-810.

[11] 沈 吉. 湖泊沉积研究的历史进展与展望. 湖泊科学,2009,21(3): 307-313.

[12] Dearing JA, Yang XD, Dong XH et al. Extending the timescale and range of ecosystem services through paleoenvironmental analyses, exemplified in the lower yangtze basin. Proceedings of the National Academy of Sciences, 2012, 109(18): E1111-E1120.

[13 ] Dong XH, Anderson NJ, Yang XD et al. Carbon burial by shallow lakes on the Yangtze floodplain and its relevance to regional carbon sequestration. Global Change Biology, 2012, 18(7) : 2205-2217.

[14] 沈 吉,薛 滨, 吴敬禄等. 湖泊沉积与环境演化. 北京: 科学出版社, 2010.

[15] Smol JP. Pollution of lakes and rivers: A paleoenvironmental perspective (Second Edition). Oxford: Wiley-Blackwell, 2008.

[16] Jeppesen E, Madsen EA, Jensen JP et al. Reconstructing the past density of planktivorous fish and trophic structure from sedimentary zooplankton fossils: a surface sediment calibration data set from shallow lake. Freshwater Biology, 1996, 36 (1) : $115-127$.

[17] Odgaard BV. Fossil pollen as a record of past biodiversity. Journal of Biogeography, 1999, 26(1) : 7-17.

[18 ] Davis MB. Erosion rates and land-use history in southern michigan. Environmental Conservation, 1976, 3(2) : 139-148.

[19] Sugita S. Theory of quantitative reconstruction of vegetation i: Pollen from large sites reveals regional vegetation composition. The Holocene, 2007, 17 (2) : 229-241.

[20] Sugita S. Theory of quantitative reconstruction of vegetation ii: All you need is love. The Holocene, 2007, 17 (2): $243-257$.

[21] Fritz SC, Ito E, Yu Z et al. Hydrologic variation in the Northern Great Plains during the last two millennia. Quaternary Research, 2000, 53: 175-184.

[22] Heinrichs ML, Walker IR. Fossil midges and palaeosalinity: Potential as indicators of hydrological balance and sea-level change. Quaternary Science Reviews, 2006, 25(15) : 1948-1965.

[23 ] Barber KE. Peatlands as scientific archives of past biodiversity. Biodiversity and Conservation, 1993, 2(5): 474-489.

[24] Sayer C, Roberts N, Sadler J et al. Biodiversity changes in a shallow lake ecosystem: A multi-proxy palaeolimnological analysis. Journal of Biogeography, 1999, 26(1) : 97-114.

[25] Alin SR, O' Reilly, Cohen AS et al. Effects of land-use change on aquatic biodiversity: A view from the paleorecord at Lake Tanganyika, East Africa. Geology, 2002, 30(12): 1143-1146.

[26] Anderson NJ, Rippey B, Gibson C. A comparison of sedimentary and diatom-inferred phosphorus profiles: Implications for defining pre-disturbance nutrient conditions. Hydrobiologia, 1993, 253 (1) : 357-366.

[27] Yang XD, Anderson NJ, Dong XH et al. Surface sediment diatom assemblages and epilimnetic total phosphorus in large, shallow lakes of the Yangtze floodplain: their relationships and implications for assessing long-term eutrophication. Freshwater Biology, 2008, 53(7): 1273-1290.

[28] Liu EF, Shen J, Yang LY et al. Assessment of heavy metal contamination in the sediments of Nansihu Lake Catchment, China. Environmental Monitoring and Assessment, 2010, 161(1) : 217-227. 
[29] Korsman T, Birks HJB. Diatom-based water chemistry reconstructions from northern Sweden: A comparison of reconstruction techniques. Journal of Paleolimnology, 1996, 15(1): 65-77.

[30] Foster GC, Chiverrell RC, Harvey AM et al. Catchment hydro-geomorphological responses to environmental change in the Southern Uplands of Scotland. The Holocene, 2008, 18(6) : 935-950.

[31] Seppä H, Alenius T, Muukkonen P et al. Calibrated pollen accumulation rates as a basis for quantitative tree biomass reconstructions. The Holocene, 2009, 19(2):209-220.

[32] Hollander DJ, McKenzie JA. $\mathrm{CO}_{2}$ control on carbon-isotope fractionation during aqueous photosynthesis: A paleo-pCO $\mathrm{pO}_{2}$ barometer. Geology,1991,19(9) :929-932.

[33 ] Downing JA, Cole JJ, Middelburg JJ et al. Sediment organic carbon burial in agriculturally eutrophic impoundments over the last century. Global Biogeochemical Cycles, 2008, 22(1): GB1018.

[34] Cole JJ, Prairie YT, Caraco NF et al. Plumbing the global carbon cycle: integrating inland waters into the terrestrial carbon budget. Ecosystems, 2007, 10(1): 171-184.

[35] 巢湖市地方志编纂委员会. 巢湖市志. 合肥: 黄山书社, 1992.

[36］巢湖市地方志办公室. 居巢简志(2000-2011). 合肥: 黄山书社,2012.

[37] Chen X, Yang XD, Dong XH et al. Nutrient dynamics linked to hydrological condition and anthropogenic nutrient loading in Chaohu Lake (southeast China). Hydrobiologia, 2011, 661 (1) : 223-234.

[38 ] Nicholson E, Mace GM, Armsworth PR et al. Priority research areas for ecosystem services in a changing world. Journal of Applied Ecology, 2009, 46(6) : 1139-1144.

[39] Anderson NJ, Korsman T, Renberg I. Spatial heterogeneity of diatom stratigraphy in varved and non-varved sediments of a small, boreal-forest lake. Aquatic Sciences, 1994, 56(1) : 40-58. 